\title{
GRAFITES E PICHAÇÕES: AS EXPRESSÕES DE ARTE URBANA DE ARAGUAÍNA (TO)
}

\author{
Graffit and Tagging: Expressions of urban art in Araguaina (TO) \\ Grafitis y Pintadas: Las expresiones de arte urbana de Araguaina (TO)
}

\section{José Ricarto da Silva Neto*"1, Jean Carlos Rodrigues ${ }^{2}$}

${ }^{1}$ Graduado em Geografia, Curso de Graduação em Geografia, Universidade Federal do Tocantins, Araguaína, Brasil.

${ }^{2}$ Professor do Curso de Graduação em Geografia, Universidade Federal do Tocantins, Araguaína, Brasil.

*Correspondência: Colegiado de Geografia/GEPCULT - Universidade Federal do Tocantins, Av. Paraguai, s/n, Araguaína, Tocantins, Brasil.CEP:77824-836.E-mail: jeancarlos@uft.edu.br

\section{RESUMO}

O representar espacial-geográfico sempre esteve associado com a elaboração de imagens, e encontramos na literatura da área diversos estudos que debatem a relação geografia e arte, espaço e imagem, paisagem e pintura, como o fizeram Ferraz (2009), Oliveira Jr. (2009), Seemann (2009), Marandola Jr. (2010), dentre muitos outros pesquisadores. No caso específico desta pesquisa que realizamos em Araguaína (TO), os estudos que envolvem geografia e arte se voltam para a cultura urbana intrigando geógrafos, urbanistas e arquitetos sobre a manifestação da arte urbana e sua comunicação em cores e formas nas paredes das cidades, como os grafites. Mas não somente isso: as palavras e os símbolos com expressões geralmente políticas, também se expressam nestas paredes demarcando no mapa da cidade a presença de grupos sociais que reivindicam seu direito a usufruir da cidade manifestadas nas pichações em espaços urbanos públicos.

Palavras-chave: Arte de rua; formas simbólicas; grafite e pichação.

\section{ABSTRACT}

Spatial-geographic representation has always been associated with the elaboration of images, and in the literature we find a number of studies that investigate the relationship between geography and art, space and image, and landscape and painting, such as the studies of Ferraz (2009), Oliveira Jr. (2009), Seemann (2009) and Marandola Jr. (2010), among many other researchers. In the specific case of our research carried out in Araguaina (TO), studies exploring geography and art turn to the urban culture intriguing geographers, urban planners and architects through manifestations of urban art and its communication with colors and shapes on city walls, in the form of graffiti. Moreover, the words and symbols of a generally political nature are also expressed on these walls, demarcating on the city map the presence of social groups that claim their right to use the city through their tagging in public urban spaces.

Keywords: Street art; symbolic shapes; graffiti and tagging.

\section{RESUMEN}

El representar espacial-geográfico siempre estuvo asociado con la elaboración de imágenes, y encontramos en la literatura de esta área diversos estudios que debaten la relación geografía y arte, espacio e imagen, paisaje y pintura, como lo hicieron Ferraz (2009), Oliveira Jr. (2009), Seemann (2009), Marandola Jr. (2010), entre muchos otros investigadores. En el caso específico de esta investigación que realizamos en Araguaína (TO), los estudios que involucran geografía y arte se vuelven para la cultura urbana intrigando a geógrafos, urbanistas y arquitectos a través de la manifestación del arte urbano y su comunicación por colores y formas en las paredes de las ciudades, como los grafitis. Pero no solamente esto: las palabras y los símbolos de manifestación generalmente política también se expresan en estos muros, demarcando en el mapa de la ciudad la presencia de grupos sociales que reivindican su derecho a disfrutar de la ciudad bajo pintadas en los espacios urbanos públicos.

Palabras-clave: Arte urbano; formas simbólicas; grafitis y pintadas. 


\section{INTRODUÇÃO}

Estabelecer uma relação entre a arte e a geografia é sempre se expor a um desafio epistemológico. Desde os tempos da institucionalização dessa ciência em meados do século XIX - e antes disso ainda, no século XVIII com Alexander von Humboldt - a geografia falava para si e para os outros por meio de representações, sobretudo mapas e cartografias de terras conhecidas, e de outras que se estava a conhecer.

Dessa forma, tratar do espaço era uma maneira de tratar de imagens, também. Os primeiros geógrafos também eram desenhistas que utilizavam das imagens para fazer ciência. $O$ representar geográfico sempre estava associado com a imagem, e até hoje encontramos na literatura da área diversos estudos que envolvem geografia e arte, sobretudo nos estudos sobre pintura, como o fizeram Ferraz (2009), Oliveira Jr. (2009), Seemann (2009), Marandola Jr. (2010), dentre muitos outros pesquisadores.

No caso específico desta pesquisa que realizamos no âmbito do Programa de Iniciação Cientifica (PIBIC/CNPq), os estudos que envolvem arte e espaço se voltam para a cultura urbana intrigando geógrafos, urbanistas e arquitetos quando a cultura urbana se expressa em cores e formas nas paredes das cidades, em forma de grafite. Mas não somente isso: as palavras e expressões de ordem, geralmente politicas, também se expressam nestas paredes demarcando no mapa das cidades a presença de grupos sociais que reivindicam seu direito a usufruir da cidade: são as pichações.

Desde então, grafites e pichações ora apavoram ora enriquecem a cultura urbana do século XX-XXI. E a geografia foi provocada, assim como outras áreas do saber, a dar respostas (ou a fazer perguntas?) sobre essas formas que ganham vida e destaque na agitada vida urbana já há algum tempo. Tratando essas manifestações da arte enquanto forma simbólica baseados na filosofia de Ernst Cassirer, a geografia ganha um amplo espaço para discutir a vida urbana sobre arte de rua. As "formas significantes" (LANGER, 2011) dos grafites e pichações podem ser exploradas de várias maneiras, e tratamos aqui de pensá-las enquanto formas significantes no espaço urbano de Araguaína/TO.

Em pesquisa anterior (PIBIC 2018-2019) denominada "Espaço e Arte: a arte de rua (grafite) como forma simbólica no espaço urbano de Araguaína (TO)" propomos, de modo geral, "analisar a produção de arte de rua (grafite) em Araguaína (TO) a partir da concepção de formas simbólicas urbanas, de E. Cassirer". Contudo, ao decorrer da pesquisa, reconhecemos a pichação como uma forma de representação desse universo simbólico, além de expressões políticas da cidade. Partindo de tal provocação, a atual pesquisa (PIBIC 2019-2020) teve como objetivo analisar o grafite e a pichação como expressão da arte urbana de Araguaína (TO) e construir um debate sobre a consideração da pichação como uma forma artística urbana, além de observar a crescente desses agentes políticos na paisagem da cidade.

\section{MATERIAIS E MÉTODOS}

Como toda pesquisa acadêmica, o presente trabalho teve como primeira etapa de elaboração, a realização de um levantamento bibliográfico em artigos e livros relacionados ao tema. Como procedimento empírico, realizamos trabalho de campo para elaboração de registro fotográfico dos grafites e pichações encontrados nas ruas e avenidas da cidade de Araguaína (TO). Como procedimento teóricometodológico, optamos por problematizar os grafites e as pichações como arte consideradas como formas simbólicas na filosofia de Ernst Cassirer. Armando Silva (2001) também se fez presente no referencial teórico da pesquisa. 
Incluímos nesta pesquisa as pichações como fenômenos de análise por reconhecermos nela tanto um fazer artístico como também um instrumento político de reivindicação pelo direito à cidade de grupos sociais muito específicos, que reivindicam seu direito à cidade por meio de suas manifestações simbólicas registradas nas paredes urbanas. Como dito na introdução desta pesquisa, a pichação tem seu reconhecimento como arte mas também como fazer político. Trabalhar com elas é reconhecer o que tem sido dito nas paredes e muros da cidade de Araguaína (TO).

\section{RESULTADOS E DISCUSSÃO}

(I) O ESPAÇO DA ARTE DE RUA EM

\section{ARAGUAÍNA: GRAFITES E PICHAÇÕES COMO EXPRESSÕES ESPACIAIS}

Araguaína é um município que pertence ao Estado do Tocantins e está localizada na região norte desta unidade da federação. Emancipada na década de 1950 ainda como um município goiano pela lei estadual n. ${ }^{\circ}$ 2.125, de 14-11-1958, Araguaína concentra a $2^{\mathrm{a}}$ maior população entre os municípios tocantinenses com uma estimativa do IBGE (2020) superior a 183 mil habitantes.

Considerada como uma cidade média, "impressiona a velocidade com que [Araguaína] atrai contingente populacional e passa de pequena cidade para cidade de porte médio em apenas meio século" (ANTERO, 2016, p. 232). De acordo com o autor, o recorte temporal para apurar tal velocidade de crescimento, se inicia na década de 1950 (período de emancipação) e alcança seu apogeu na década de 2010 e sequente.

Tal transformação foi impulsionada pela estratégica posição territorial de Araguaína (norte do Tocantins, próxima à fronteira com os Estados do Pará e
Maranhão, além de sua inserção na demarcação regional da Amazônia Legal, sobretudo após a criação do Estado do Tocantins no fim da década de 1980). Além disso, grandes projetos de infraestrutura da década de 1960 e seguintes, como a construção da BR-153, teria provocado grande impulso populacional no município, sobretudo com intensificação da migração ruralurbana e inter-regional, conforme apontado por Antero (2016, p. 229).

Tal processo migratório, além de resultar no aumento veloz da população em Araguaína, também colaborou com as manifestações simbólicas no município. Diversos bairros, ruas e avenidas da cidade trazem consigo nomenclaturas que lembram esses movimentos e que contribuem para a formação cultural do município no sentido de preservar, e ao mesmo tempo cartografar, os espaços simbólicos dos migrantes. Segundo Antero (2016, p. 237), “a presença de antigos e recentes migrantes nordestinos residindo em bairros com denominações simbólicas de suas origens, como Vila Piauí e Vila Maranhão são indicativos da urbanização de Araguaína (...)".

Entretanto, destaca-se que embora tal espaço simbólico se manifeste nesse toponímico historicamente associado ao processo de migração que em muito contribuiu, não apenas com o aumento populacional do município, mas também com o desenvolvimento de suas atividades comerciais e industriais haja vista seu posicionamento territorial estratégico como apontado acima, as manifestações simbólicas pelo espaço urbano do município também se manifestam de outras formas, como a presença de pichações e dos grafites, mesmo que de maneira ainda muito tímida, mas não sem um significado.

Isso significa que a arte do grafite se torna visível pelo espaço urbano de Araguaína, o que significa considerar que este espaço urbano, locus das contradi- 
ções e dos conflitos, também se apresenta como espaço da arte apropriado pelo grafite de uma maneira distinta. Segundo Blauth e Possa (2012, p. 152), “o grafite, atualmente, já faz parte do dia-a-dia dos espaços urbanos, principalmente das grandes cidades do mundo, e vem sendo legitimado como uma manifestação artística que rompe com padrões estéticos de percepção e apreensão convencional da arte".

Mas nem sempre foi assim: com origem na década de 1970 nos Estados Unidos, o grafite era, “(...) inicialmente, considerado um ato de vandalismo pela sociedade, fortemente associado à marginalidade e à delinquência" (BLAUTH, POSSA, 2012, p. 154). Em Araguaína, em específico, é difícil mensurar quando as primeiras manifestações de grafites tenham surgido na cidade, mas pode-se considerar que essas formas de expressões artísticas urbanas têm adquirido impulso e visibilidade na última década com forte presença, sobretudo, nos desenhos de fachadas de lojas, bares, pizzarias e academias, além de outros espaços urbanos de circulação de pessoas.

Segundo Blauth e Possa (2012, p. 153), a natureza do grafite “(...) é efêmera, abordando temas desde a crítica social, política e econômica, muitas vezes com ironia ou humor, sendo, principalmente, desprovido da ideia de consumo, tornando-se acessível para o público transeunte". Isso faz toda a diferença em termos da construção das espacialidades da arte, haja vista que tanto para a prática quanto para a percepção do grafite contemporâneo, basta se colocar no espaço publico da cidade.

Por outro lado, quando se trata da pichação, Blauth e Possa (2012), com referência em Gitahy (1999), apontam que elas

(...) pertencem a outro grupo de artistas de rua, cujo intuito é interferir em muros, mo- numentos e fachadas arquitetônicas, com rabiscos, frases de protestos, insultos, que leigos não conseguem decifrar, como uma forma de identificação e demarcação de territórios entre grupos, algumas vezes, rivais (BLAUTH, POSSA, 2012, p. 153).

Nesse sentido, as pichações revelam as disputas territoriais pelo espaço urbano que acontecem entre grupos diversos, que possuem nesse tipo de manifestação a construção de uma linguagem de grupo que almeja visibilidade em um contexto espacial no qual o status quo os colocam na invisibilidade social. A pichação se apresenta, portanto, mais como um discurso-que-faz-aparecer em muros e monumentos da cidade como forma de expressão daqueles que reivindicam o direito de estar-na-cidade e de se manifestar nela.

E essa postura não é recente. No contexto histórico que retrata as origens da pichação, Blauth e Possa (2012, p. 153) dizem que

a origem da pichação pode ser atribuída aos xingamentos, cartazes eleitorais, anúncios e poesias que foram encontradas em paredes da cidade de Pompeia, ou mesmo na Idade Média, no período da inquisição, quando os padres pichavam com betume as paredes dos conventos de ordens que não lhes eram simpáticos. Em anos posteriores, paredes de casas eram pichadas com o intuito de atacar seus moradores, como uma forma de denunciar por algum ato não aceito pela sociedade. $\mathrm{O}$ ato de pichar, por ser ilegal e subversivo, era e ainda é, executado à noite, nas madrugadas, para poder driblar o policiamento. 
Nessa perspectiva, se torna presente o fato de que a pichação sempre esteve relacionada com atos de demarcações-de-espaços, com intenções diversas. Anônimos ou codificados para que poucos possam reconhecer e identificar seus autores, nas pichações estão sempre presentes as intenções de dizer-algumacoisa, ou seja, de manifestar uma ideia, uma denúncia, uma reflexão, um pensamento que tem, no espaço urbano, a condição sine qua non de conquistar visibilidade pública mas não, necessariamente, concordância com a mensagem.

Embora tanto a pichação quanto o grafite sejam manifestações no espaço urbano, existem diversas diferenças entre essas duas expressões de arte. $\mathrm{Na}$ pichação reconhece-se letras e palavras como meiode-se-fazer, enquanto no grafite predomina desenhos $\mathrm{e}$ cores. Além disso, outros elementos diferenciam uma expressão da outra:

os pichadores competem pelo espaço a ser pichado, diferentemente dos grafiteiros, que respeitam os espaços já grafitados. Procuram pichar os locais mais altos e de difícil acesso, incluindo monumentos públicos, ao contrário dos grafiteiros, cujo intuito é chamar a atenção dos transeuntes para sua produção artística, (BLAUTH, POSSA, 2012, p. 153).

Mas ambas (grafite e pichação) podem ser tratadas na geografia como um estudo de imagem, mas de uma imagem envolvida com o contexto urbano, a qual pode dar visibilidade a todos os conflitos e confrontos de ordem social, política, ética e estética da própria cidade, de seu entorno ou mesmo do mundo. Dessa forma, a escala não impõe limite à representação que se elabora e faz-aparecer no espaço urbano local. A arte como pensamento significa as coisas do mundo. Para Marandola Jr. (2010, p. 15), “arte é pensamento, construído e materializado num determinado símbolo-imagem".

Segundo Oliveira (2009, p. 20), “imagens desejam que miremos o espaço sob a perspectiva que elas nos dão dele. Buscam gestar e perpetuar uma maneira de imaginar o espaço". E o autor avança: "muitas dessas imagens-que-dizem-do-mundo querem ser vistas como o próprio real manifestando-se diante de nós" (OLIVEIRA, 2009, 21). Desse modo, corroboramos com Cassirer (2005), quando o autor enfatizou que a arte não apenas cria mundos, mas os torna visíveis, os faz presente.

\section{(II) ARTE COMO FORMA SIMBÓLICA NA FILOSOFIA DE ERNST CASSIRER}

Para E. Cassirer, a arte (assim como a linguagem, a ciência, a religião e o mito) é uma forma simbólica. Segundo o filósofo alemão, “a arte nos apresenta os movimentos da alma humana em toda a sua profundidade e variedade" (CASSIRER, 2005, p. 244). Com tal proposta, Cassirer (2005) nos revela que os sentimentos mobilizados na e pela arte manifestam-se como sendo elementos da dinâmica da própria vida. Assim, "um grande pintor ou músico não é caracterizado por sua sensibilidade à cor ou aos sons, mas por seu poder de extrair de seu material estático uma vida dinâmica de formas" (CASSIRER, 2005, p. 261-262).

De acordo com o filósofo alemão, "nela [arte], vivemos mais no domínio das formas puras do que no da análise e escrutínio de objetos sensoriais, ou do estudo de seus efeitos" (CASSIRER, 2005, p. 236). Nesse sentido, a arte está no mundo, o que implica em considerar que os contextos temporal e espacial que compõem a vida do artista tomam cores e formas em suas obras. As experiências vividas pelo artista em seu 
mundo circundante representadas em suas artes constituem formas simbólicas que nos permitem (re)conhecer a maneira como cada artista retrata a realidade.

Para Fischer (2007, p. 17) "toda arte é condicionada pelo seu tempo e representa a humanidade em consonância com as idéias e aspirações, as necessidades e as esperanças de uma situação histórica particular". Isto significa que a produção artística pode derivar das experiências que os sujeitos possuem do mundo que o cerca, seu mundo circundante (TORRES, 2019). Segundo Fischer (2007, p. 14) “(...) a arte não só precisa derivar de uma intensa experiência da realidade como precisa ser construída, precisa tomar forma através da objetividade". A arte produzida, como representação, apreende os objetos, as emoções e os sentimentos, e significa o espaço e o mundo no processo de sua criação.

Entretanto, ela não fica restrita apenas à materialidade uma vez que a espacialidade também contém o percebido, o concebido e o vivido pelo artista. Segundo Gil Filho (2003, p. 05), “a espacialidade seria construída a partir do imbricamento do movimento tríade do espaço percebido, concebido e vivido", embora este cruzamento, segundo o autor, não seja simples nem estável. Desta forma, para além da materialidade objetiva das coisas, a perspectiva espacial também contempla o existencial naquilo que é percebido, concebido e vivido pelo ser.

Isto implica em um processo de clareza, objetividade e sensibilidade do artista no processo de criação, ou seja, ele precisa exercer domínios tanto técnico quanto emocional no momento da produção. Para Cassirer (2005), todo artista é criador de formas simbólicas, e não um imitador da realidade. Segundo
Fischer (2007, p. 14), “o trabalho para um artista é um processo altamente consciente e racional, um processo ao fim do qual resulta a obra de arte como realidade dominada, e não - de modo algum - um estado de inspiração embriagante".

Assim, o percebido, o concebido e o vivido objetiva-se em telas dando formas, cores e traços às experiências espaciais do artista e às suas representações. Este "tomar forma" no qual se refere Fischer (2007) envolve um complexo processo de criação no qual imaginário, técnica e memória se articulam no processo da construção da arte. Segundo Fischer (2007, p. 14), “para conseguir ser um artista, é necessário dominar, controlar e transformar a experiência em memória, a memória em expressão, a matéria em forma". A referência à experiência neste processo confirma o que afirmamos anteriormente: a arte não está fora do mundo, ela representa o mundo.

Neste sentido, podemos inferir que o olhar do espectador ao se deparar com uma obra artística criada em outros períodos, é sempre o olhar de quem observa e não de quem criou. Ou seja, os significados atribuídos à obra artística são aqueles dados pelo observador. Katuta (2012, p. 59), ao estabelecer um diálogo no mesmo sentido sobre as imagens, afirma que existem relações diferentes entre produtor e observador, “(...) até mesmo porque podem [as imagens] ser produzidas em uma determinada espaço temporalidade e observadas-apreendidas em outras".

Nesse sentido, "a existência [da obra] depende do indivíduo que a apreende" (GOMES, 2001, p. 70). Esse é o paradoxo que Langer (2011) havia exposto sobre a expressão versus a impressão; o artista versus o observador. A arte constitui uma instância que atribui sentido ao mundo. Nesse sentido, a arte como produtora de imagens, e imagens-de-espaço, nos provoca a pensarmos sobre os sentidos e significados 
que são atribuídos às espacialidades humanas por ela criada. Desta forma, "as imagens, sobretudo as de espaço, constituem-se em instrumentos cognitivos fundamentais para a construção de nosso pensamento" (KATUTA, 2012, p. 56).

\section{(III) IMAGENS DA CIDADE: GRAFITES E PICHAÇÕES EM ARAGUAINA (TO)}

Em Araguaína, é possível reconhecer tanto o grafite quanto a pichação em diversos espaços da cidade, com usos diferentes. Via de regra, eles se encontram, por exemplo, em academias, nas fachadas de bares, restaurantes e lojas e nas praças e locais públicos, de livre circulação, da cidade. Neste trabalho, apresentaremos alguns exemplares.

Descrito por Cassirer (2005) como "uma chave para a natureza do homem", o símbolo, ou o universo simbólico humano, é o fator responsável para que o homem possa construir e se identificar com/no mundo. Ainda para o autor, "a realidade não é uma coisa singular e homogênea; é imensamente diversificada, e tem tantos esquemas e padrões diferentes quanto há organismos diferentes" (CASSITER, 2005, p. 46). Neste caso, a forma simbólica que transmite o conhecimento é a linguagem.

A relação entre arte e cidade sempre está presente na produção do espaço social do homem. No caso específico da cidade de Araguaína, essa relação se torna bastante evidente quando identificamos grafites em um dos principais espaços públicos do município denominado "Parque Cimba". Este parque, localizado em uma área que na década de 1960 abrigava uma indústria denominada CIMBA, hoje a mesma área está totalmente ressignificada com novas atribuições de forma e função (SANTOS, 2006) e tornou-se um espaço de práticas de atividades físicas e de lazer. Nela, convivem as rugosidades da antiga indústria, as novas funcionalidades do espaço e grafites que atribuem à área nova perspectiva de sentidos e significados da arte urbana araguainense, conforme as figuras 1 e 2 .

\section{Figura 1: Grafite CIMBA.}

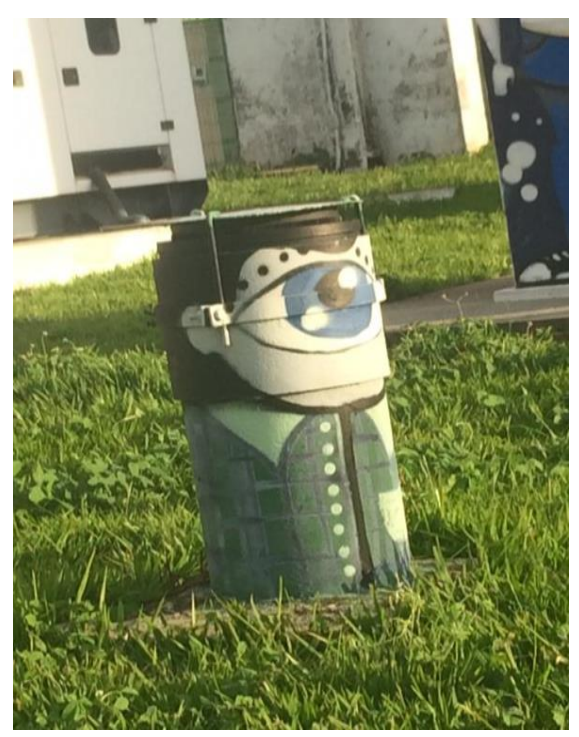

Foto: José Ricarto da Silva Neto.

Figura 2: Grafite CIMBA.

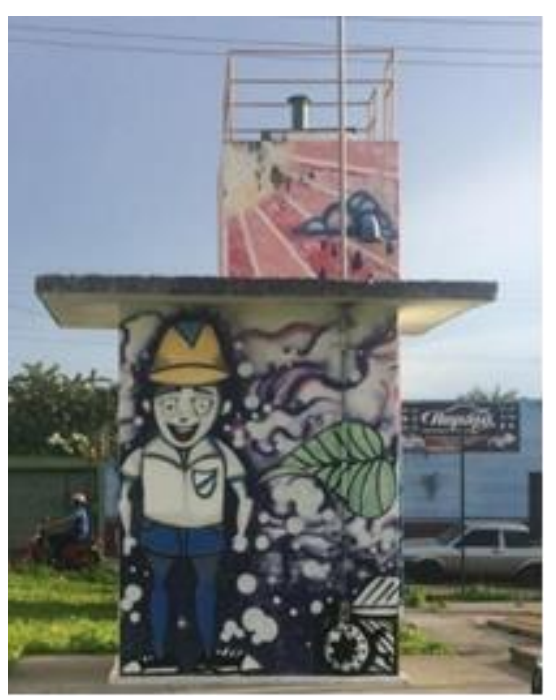

Foto: José Ricarto da Silva Neto.

Enquanto o Parque Cimba se apresenta como o "espaço do grafite", as praças São Luiz Orione 
(antiga Praça das Nações) e Praça das Bandeiras se mostram como o "espaço da pichação" em Araguaína. A figura 3 refere-se a uma pichação na Praça São Luiz Orione:

Figura 3: Pichação Praça São Luiz Orione.

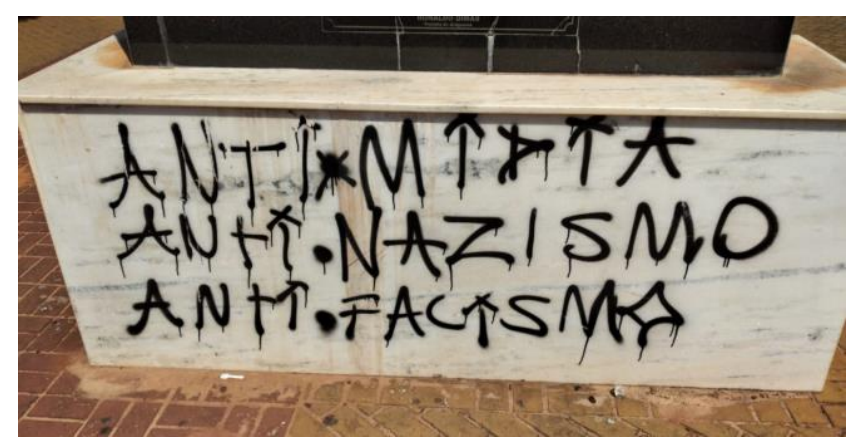

Foto: José Ricarto da Silva Neto

Com relação à Praça das Bandeiras, onde fica localizado o Restaurante Popular de Araguaína, as figuras 4 e 5 retratam uma pichação naquele local:

Figura 4: Pichação Praça das Bandeiras.

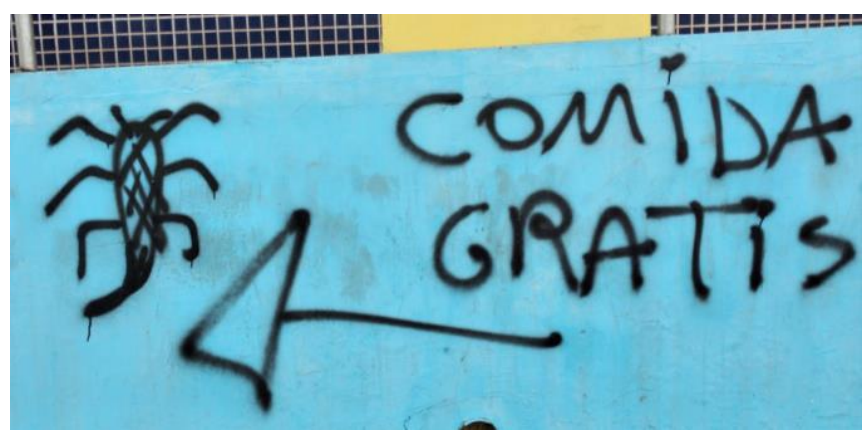

Foto: José Ricarto da Silva Neto.

Figura 5: Pichação Praça das Bandeiras.

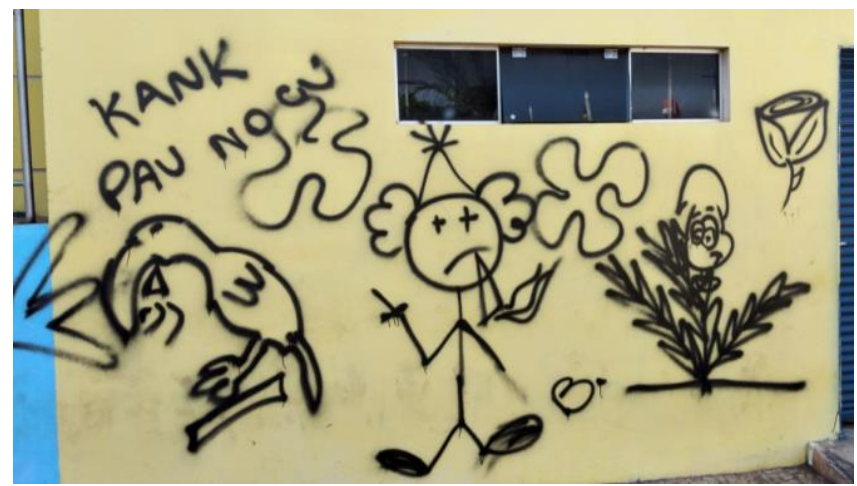

Foto: José Ricarto da Silva Neto.

Conforme apontado pela abordagem teórica deste artigo, as pichações seguem o padrão de não identificar seus autores, mas constituírem-se de manifestações e expressões no espaço urbano fazendo referência a fatos políticos ou outro tipo de referências de ordem social. Dessa forma, verifica-se que a arte, enquanto manifestação simbólica, expressa a consciência de indivíduos e grupos, que tem nela seu referencial de criação, mas também de protesto, por meio de seus signos/chaves. Os signos são as "chaves" para que se possa entender os símbolos ou o "universo simbólico". Em outras palavras, para que se consiga entender o que uma Pichação tem a nos dizer, são necessárias "chaves" para que se possa fazer a leitura para além do que está exposto assim como na arte, ver o visível do invisível que a obra contém.

\section{CONCLUSÃO}

Em decorrência da construção do presente trabalho, reconhecemos a pichação como uma forma de representação artística do universo simbólico para além dos instrumentos políticos vistos nessas manifestações. Tanto grafites quanto pichações se tornam visíveis no espaço urbano de Araguaína e, na geografia, observamos através de estudos de imagens. Sendo que a segunda revela disputas territoriais e é um discurso-que-faz-aparecer.

Consideramos a pichação como tal, pois a arte como pensamento significa as coisas do mundo, tendo em vista que cada uma dessas imagens é seu próprio mundo. Marandola Jr. (2010, p. 15) nos diz que a "arte é pensamento, construído e materializado num determinado símbolo-imagem". Desta forma, então, são constituídos grafites e pichações. Sendo assim, mesmo com tais diferenças vistas no trabalho, ambas 
são formas simbólicas que fazem o mundo do homem

"mundo".

\section{AGRADECIMENTO}

O presente trabalho foi realizado com o apoio do Conselho Nacional de Desenvolvimento Científico e Tecnológico - CNPq - Brasil.

Todos os autores declararam não haver qualquer potencial conflito de interesses referente a este artigo.

\section{REFERÊNCIAS}

ANTERO, Roberto. Urbanização pela migração em Araguaína (TO). Caminhos de Geografia, v. 17, n. 59, p. 228-243, 2016.

BLAUTH, Lurdi; POSSA, Andrea C. K. Arte, grafite e o espaço urbano. Palíndromo, n. 08, 2012, p. 146163.

CASSIRER, Ernst. Ensaio sobre o homem. Introdução a uma filosofia da cultura humana. São Paulo: Martins Fontes, 2005.

DAL GALLO, P.M.; MARANDOLA JR, E. O conceito fundamental de mundo na construção de uma ontologia da geografia. Geousp - Espaço e Tempo (Online), v. 19 , n. 3, p. 551-556, mês. 2016. ISSN 2179-0892.

FERRAZ, Claudio B. Oliveira. Geografia: o,olhar e a imagem pictórica. Pro-Posições, v. 20, n.3 (60), p. 29 41, 2009.

FISCHER, Ernest. A Necessidade da Arte. $9^{\text {a }}$ ed. Rio de Janeiro, LTC, 2007.

GIL FILHO, Sylvio Fausto. Geografia Cultural: estrutura e primado das representações. Espaço e Cultura, Rio de Janeiro, n. 19-20, p, 51-59, 2005.

Espaço de Representação: uma categoria chave para a análise cultural em Geografia, 2003. Disponível http://faustogil.ggf.br/gilfilho/arquivos/espacorepresentacao-geografia.pdf. Acesso em: 17.08.2020.

GOMES, Edvânia T. Aguiar. Natureza e Cultura representações na paisagem. In: ROSENDAHL, Zeny; CORREA, Roberto Lobato (Orgs). Paisagem, Imaginário e Espaço. Rio de Janeiro: Eduerj, 2001, p. $49-70$.

MARANDOLA JR., Eduardo. Humanismo e arte para uma geografia do conhecimento. Geosul, v. 25, n. 49, p. 07-26, 2010.

Fenomenologia e Pós-Fenomenologia: alternâncias e projeções do fazer geográfico humanista na geografia contemporânea. Geograficidade, v. 3, n. 2, p. 49-64, 2013.

KATUTA, Angela Massumi. As imagens na Geografia: coordenadas semióticas para a compreensão para a ordenação dos lugares. Estudos Geográficos, n. 10(1), p. 54-71, 2012.

LANGER, Susanne K. Sentimento e Forma: uma teoria da arte desenvolvida a partir de Filosofia em nova Chave. São Paulo: Perspectiva, 2011.

OLIVEIRA JR., Wencelau Machado de. Grafar o espaço, educar os olhos. Rumo a geografias menores. Pro-Posições, v. 20, n.3 (60), p. 17-28, 2009.

SEEMANN, Jorn. Arte, conhecimento geográfico e leitura de imagens: O geógrafo, de Vermeer. ProPosições, v. 20, n.3 (60), p. 43-60, 2009.

SANTOS, Milton. A Natureza do Espaço: Técnica e Tempo, Razão e Emoção. São Paulo: Editora Universidade de São Paulo, 2006.

SILVA, Armando. Imaginários Urbanos. São Paulo: Perspectiva; Bogotá, Col: Convênio Andres Bello, 2001.

TORRES, Marcos Alberto. As formas simbólicas e a paisagem. In: GIL FILHO, Sylvio Fausto; SILVA, Marcia Alves Soares da; GARCIA, Rafael Rodrigues. Ernst Cassirer: Geografia e Filosofia. Curitiba: Programa de Pós-Graduação em Geografia - UFPR, 2019, p. 308-334. 